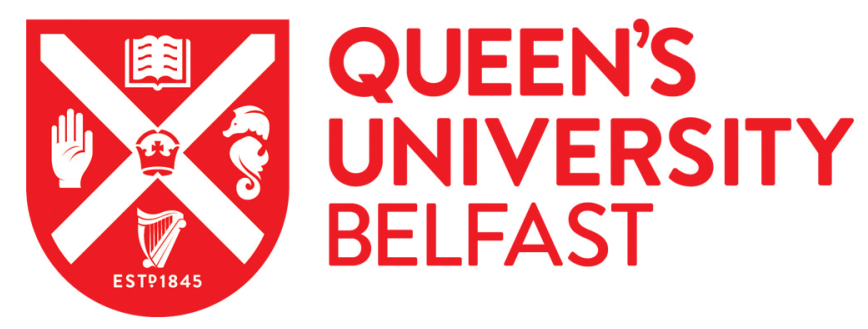

\title{
Efficacy and safety of the elexacaftor plus tezacaftor plus ivacaftor combination regimen in people with cystic fibrosis homozygous for the F508del mutation: a double-blind, randomised, phase 3 trial
}

VX17-445-103 Trial Group (2019). Efficacy and safety of the elexacaftor plus tezacaftor plus ivacaftor combination regimen in people with cystic fibrosis homozygous for the F508del mutation: a double-blind, randomised, phase 3 trial. Lancet, 394(10212), 1940. https://doi.org/10.1016/S0140-6736(19)32597-8

Published in:

Lancet

Document Version:

Peer reviewed version

Queen's University Belfast - Research Portal:

Link to publication record in Queen's University Belfast Research Portal

Publisher rights

Copyright @ 2019 Elsevier Inc. except certain content provided by third parties.

This manuscript version is made available under the CC-BY-NC-ND 4.0 license http://creativecommons.org/licenses/by-nc-nd/4.0/,which permits distribution and reproduction for non-commercial purposes, provided the author and source are cited.

\section{General rights}

Copyright for the publications made accessible via the Queen's University Belfast Research Portal is retained by the author(s) and / or other copyright owners and it is a condition of accessing these publications that users recognise and abide by the legal requirements associated with these rights.

\section{Take down policy}

The Research Portal is Queen's institutional repository that provides access to Queen's research output. Every effort has been made to ensure that content in the Research Portal does not infringe any person's rights, or applicable UK laws. If you discover content in the

Research Portal that you believe breaches copyright or violates any law, please contact openaccess@qub.ac.uk. 


\section{Efficacy and safety of the elexacaftor/tezacaftor/ivacaftor combination regimen in people} with cystic fibrosis homozygous for the F508del mutation: a double-blind, randomised, phase 3 trial

\section{Harry G M Heijerman, MD, ${ }^{1, *}$ Edward F McKone, MD, ${ }^{2, *}$ Damian G Downey, MD, ${ }^{3}$ Eva Van} Braeckel, MD, ${ }^{4}$ Steven M Rowe, MD, ${ }^{5}$ Elizabeth Tullis, MD, ${ }^{6}$ Marcus A Mall, MD, ${ }^{7}$ John J Welter, $\mathrm{MD},{ }^{8}$ Bonnie W Ramsey, MD, ${ }^{9}$ Charlotte M McKee, MD, ${ }^{10}$ Gautham Marigowda, MD, ${ }^{10}$ Samuel M Moskowitz, MD, ${ }^{10}$ David Waltz, MD, ${ }^{10}$ Patrick R Sosnay, MD, ${ }^{10}$ Christopher Simard, MD, 10 Neil Ahluwalia, MD, ${ }^{10}$ Fengjuan Xuan, PhD, ${ }^{10}$ Yaohua Zhang, PhD,${ }^{10}$ Jennifer L Taylor-Cousar, $M D,{ }^{11, *}$ Karen S McCoy, MD ${ }^{12, *}$ on behalf of the VX17-445-103 Trial Group

${ }^{*}$ Equal contributions

${ }^{1}$ Department of Pulmonology, University Medical Center Utrecht, Utrecht, the Netherlands; ${ }^{2} \mathrm{St}$ Vincent's University Hospital and University College Dublin School of Medicine, Dublin, Ireland; ${ }^{3}$ Centre for Experimental Medicine, Queen's University Belfast, Northern Ireland, United Kingdom; ${ }^{4}$ Department of Respiratory Medicine, Ghent University Hospital, Ghent, Belgium; ${ }^{5}$ Division of Pulmonary, Allergy, and Critical Care Medicine, University of Alabama at Birmingham, Birmingham, AL, USA; ${ }^{6}$ Divison of Respirology, St Michael's Hospital, University of Toronto, Toronto, , Canada; ${ }^{7}$ Department of Pulmonology, Immunology and Intensive Care Medicine, Charité-Universitätsmedizin Berlin, Berlin Germany; Berlin Institute of Health, Berlin, Germany; and German Center for Lung Research, Berlin, Germany; ${ }^{8}$ Division of Pediatric Pulmonology, Allergy, Immunology, and Sleep Medicine, New York Medical College, Valhalla, NY, USA; 'Department of Pediatrics, Seattle Children's Hospital, University of Washington School of Medicine, Seattle, WA, US; ${ }^{10}$ Vertex Pharmaceuticals Incorporated, Boston MA, US; ${ }^{11}$ Deparment of Medicine and Pediatrics, National Jewish Health, Denver, CO, USA; 
27 12Department of Pediatrics, Nationwide Children's Hospital, Ohio State University, Columbus, $28 \mathrm{OH}, \mathrm{USA}$

29

30 Corresponding author

31 Prof Harry Heijerman, MD, PhD

32 Department of Pulmonology, University Medical Center Utrecht

33 Heidelberglaan 100 3584CX, Utrecht

34 The Netherlands

35 h.g.m.heijerman@umcutrecht.nl

36 Phone: +31887556180

37 Mobile: +31621235161

38

39 Word count: 3031 (limit: 3500 words)

40 Tables/figures: 3 tables, 4 figures (no limit specified)

41 References: 28 (limit: 30)

42 Abstract word count: 309 (limit: 300)

43 
44

\section{Summary}

\section{Background}

Cystic fibrosis transmembrane conductance regulator (CFTR) modulators correct the basic defect caused by CFTR mutations. Improvements in health outcomes have been achieved using the combination of a CFTR corrector and potentiator in people with CF (pwCF) homozygous for F508del. The addition of elexacaftor (ELX; VX-445), a next-generation CFTR corrector, to tezacaftor/ivacaftor (TEZ/IVA) further improved F508del-CFTR function and clinical outcomes in a phase 2 study in pwCF homozygous for F508del.

\section{Methods}

A phase 3, multi-centre, randomised, double-blind, active-controlled trial of ELX in triple combination with TEZ/IVA (ELX/TEZ/IVA) in pwCF homozygous for F508de/ was conducted.

Eligible participants were aged $\geq 12$ years with stable disease and percent predicted forced expiratory volume in 1 second $\left(\mathrm{ppFEV}_{1}\right)$ of 40 to 90 , inclusive. After a four-week TEZ/IVA run-in, participants were randomised 1:1 to four weeks of ELX/TEZ/IVA versus TEZ/IVA alone. The primary endpoint was absolute change from baseline (measured at the end of the TEZ/IVA runin) in $\mathrm{ppFEV}_{1}$ at week 4 . Key secondary endpoints were absolute change in sweat chloride and CF Questionnaire-Revised respiratory domain (CFQ-R RD) score. ClinicalTrials.gov, number NCT03525548.

\section{Findings}

Between August and December 2018, 113 participants were enrolled. Following the run-in, 107 participants were randomised and completed the 4-week treatment period.

The ELX/TEZ/IVA group had improvements in ppFEV 1 (10.0 percentage points, $95 \% \mathrm{Cl} 7 \cdot 4$ to 12.6, $\mathrm{p}<0 \cdot 0001)$, sweat chloride concentration $(-45 \cdot 1 \mathrm{mmol} / \mathrm{L}, 95 \% \mathrm{Cl}-50 \cdot 1$ to $-40 \cdot 1, \mathrm{p}<0 \cdot 0001)$, and CFQ-R RD score $(17 \cdot 4$ points, $95 \% \mathrm{Cl} 11 \cdot 8$ to $23 \cdot 0, \mathrm{p}<0 \cdot 0001)$ compared with the TEZ/IVA 
70 group. ELX/TEZ/IVA was well tolerated, with no discontinuations. Most adverse events were

71 mild or moderate; serious adverse events occurred in $4 \%(n=2)$ of participants receiving

72 ELX/TEZ/IVA and $2 \%(n=1)$ receiving TEZ/IVA.

73

74 Interpretation

75 ELX/TEZ/IVA provided clinically robust benefit vs TEZ/IVA alone with a favourable safety profile

76 and demonstrates the potential to lead to transformative improvements in the lives of pwCF

77 homozygous for F508del

78

79 Funding

80 Vertex Pharmaceuticals Incorporated

81

82 


\section{Research in context}

\section{Evidence before this study}

F508del, the most common defective form of the cystic fibrosis transmembrane conductance regulator protein (F508del-CFTR), can be corrected with currently available dual modulator combinations. Treatment of people with cystic fibrosis (pwCF) homozygous for F508del with these dual combinations has resulted in clinical improvements, but these improvements are lower in magnitude than those in the small subset of pwCF with genotypes highly responsive to available modulators. Addition of a next-generation CFTR corrector, elexacaftor (ELX; VX-445) to the existing CFTR modulator dual combination of tezacaftor/ivacaftor (TEZ/IVA) provided further benefit to this group of pwCF in a phase 2 study. The phase 2, double-blind, activecomparator study of ELX/TEZ/IVA in a small number of pwCF homozygous for F508del who were already receiving TEZ/IVA demonstrated that the triple drug combination was well tolerated and that the addition of ELX resulted in improvements in lung function, CFTR function, and a patient-reported outcome measure. A PubMed search of clinical trials, with no restrictions on publication date or language, using the terms "elexacaftor" and/or "VX-445" performed on 30 July 2019 revealed only one publication, describing the phase 2 study of ELX/TEZ/IVA.

\section{Added value of this study}

The trial reported here is the first phase 3 study of ELX/TEZ/IVA in pwCF homozygous for F508del. The results demonstrate, in a larger cohort, profound improvements in lung function, CFTR function, and respiratory-related quality of life compared with TEZ/IVA, along with a favourable safety profile. Evidence of systemic effect was also seen, with rapid improvements in body weight, an important predictor of survival in CF. 
Page 6

108 Implications of all the available evidence

109 The introduction of ELX/TEZ/IVA may extend highly effective CFTR modulator therapy to those

110 homozygous for F508del, a large proportion of pwCF. This advance in therapy is likely to modify

111 the natural course of the disease, leading to meaningful improvements in the lives of these

112 pwCF, profoundly impacting the face of CF care. 
113

114

\section{Introduction}

Cystic fibrosis (CF) is an autosomal recessive disease caused by mutations in the cystic fibrosis transmembrane regulator (CFTR) gene, which encodes for the CFTR protein, an anion transporter responsible for conductance of chloride and bicarbonate across epithelial surfaces in the airway, gastrointestinal and reproductive tracts, pancreas, and sweat glands. ${ }^{1}$ Absence or reduction in the quantity and/or dysfunction of CFTR results in abnormal mucus secretions and multi-organ dysfunction, including pancreatic insufficiency and airway infection and obstruction. ${ }^{1,2}$ Chronic airway infection leads to progressive lung damage and eventually respiratory failure and premature death, with a median age at death of approximately 31 years. ${ }^{3-}$ 5

Although it is known that there are more than 2000 variants of the CFTR gene,$^{6}$ the most prevalent disease-causing CFTR mutation worldwide is F508del.4,5 Up to $90 \%$ of all people with CF (pwCF) have at least one copy of this mutation, and almost $50 \%$ of pwCF are homozygous for F508del. ${ }^{3-5}$

At present, the majority of treatments for pwCF address the downstream complications of CFTR dysfunction, independent of the CFTR genetic defect. In recent years, small molecules have been developed to address the basic defect through modulation of CFTR protein function. The first CFTR modulator therapy developed and approved was ivacaftor (IVA), a highly effective CFTR modulator in pwCF with G551D. IVA successfully potentiates this CFTR protein by increasing open probability, and led to unprecedented improvements in sweat chloride (an in vivo marker of CFTR function), lung function, respiratory-related quality of life, weight, and pulmonary exacerbations, sustained over the 48-week placebo-controlled trial. ${ }^{7}$ 
138 IVA alone does not restore F508del-CFTR function; ${ }^{8}$ CFTR dysfunction caused by F508del is

139 multifactorial, with defective protein processing and trafficking to the cell surface, reduced

140 channel gating, and high turnover once at the cell surface..$^{2,9,10}$ However, these defects can be 141 partially overcome with a combination of CFTR modulators. Correctors such as lumacaftor and tezacaftor (TEZ) aid in processing and trafficking of the protein to the cell surface, and the

143 potentiator ivacaftor addresses the gating defect. Studies of lumacaftor/IVA and TEZ/IVA showed improvements in lung function (2.6-4.0 percentage points of the percentage of predicted forced expiratory volume in 1 second [ppFEV 1 ]) and decreases in the rate of pulmonary exacerbations (a 35\%-39\% reduction) in pwCF homozygous for F508del. ${ }^{11,12}$ Given the multiple defects in F508del-CFTR affecting processing and trafficking, the magnitude of clinical improvements was consistent with the degree of correction of F508del-CFTR by a single CFTR corrector. ${ }^{13,14}$ To further enhance the modulation of F508del-CFTR, it was hypothesised that the addition of a second corrector acting with a complementary mechanism of action would be necessary to more fully restore CFTR processing and trafficking to a corrector-potentiator combination.

Elexacaftor (ELX; VX-445) is a next-generation CFTR corrector that was shown, in vitro, to significantly increase the amount of mature CFTR protein and CFTR activity when added to the combination of TEZ/IVA. ${ }^{15}$ ELX/TEZ/IVA showed encouraging results in a phase 2 study of this triple combination in a small sample of pwCF homozygous for F508del. ${ }^{15}$ The current phase 3 , 4-week, randomised, controlled trial was conducted to confirm the superior efficacy of ELX/TEZ/IVA compared to TEZ/IVA and to evaluate safety in pwCF homozygous for F508del, as part of a development program that included a concurrent phase 3, 24-week, randomised, placebo-controlled trial in pwCF heterozygous for F508del. ${ }^{16}$ 
163

164

165

166

167

168

169

170

171

172

173

174

175

176

177

178

179

180

181

182

183

184

185

186

187

\section{Methods}

\section{Trial Design and Oversight}

A phase 3, multi-centre, randomised, double-blind, active-controlled trial of ELX in triple combination with TEZ/IVA in pwCF aged $\geq 12$ years homozygous for F508del (ClinicalTrials.gov number NCT03525548) was conducted at 44 sites in four countries (Belgium, the Netherlands, the United Kingdom, and the United States) from 03 August 2018 to 28 December 2018.

The primary objective of the trial was to evaluate the efficacy of ELX in triple combination with TEZ/IVA, in comparison with TEZ/IVA alone, in pwCF homozygous for the F508de/ mutation.

An independent review board or ethics committee for each site approved the trial protocol and informed-consent forms. All enrolled participants, or their legal guardians, provided written informed consent (and assent, when appropriate).

\section{Procedures}

Because treatment with lumacaftor/IVA or TEZ/IVA is standard of care for pwCF homozygous for F508del, and to ensure a reliable on-treatment baseline before the triple combination treatment period, participants completed a 4-week TEZ/IVA run-in period following a 4-week screening period as described in Taylor-Cousar et al. ${ }^{16}$ Participants then received 4 weeks of treatment with either ELX 200 mg once daily in triple combination with TEZ 100 mg once daily and IVA $150 \mathrm{mg}$ every 12 hours, or the dual combination of TEZ $100 \mathrm{mg}$ once daily and IVA 150 mg every 12 hours. All drugs were administered orally. Selection of the dose of ELX was based on data from the phase 2 dose-ranging trial. ${ }^{15}$ TEZ and IVA were used at the approved dosages in both arms (figure 1). 
188

189

190

191

192

193

194

195

196

197

198

199

200

201

202

203

204

205

206

207

208

209

210

211

212

213

\section{Randomisation and masking}

Participants were randomised in a 1:1 ratio by an interactive web response system to either ELX/TEZ/IVA or TEZ/IVA (see Supplementary Appendix for additional details). Placebo tablets were used to maintain the blind. Randomisation was stratified by $\operatorname{ppFEV}_{1}(<70$ vs $\geq 70$, as determined during the run-in period) and age ( $<18$ vs $\geq 18$ years at the screening visit). At trial completion, participants were given the option to enrol in a 96-week open-label extension trial (VX17-445-105; ClinicalTrials.gov number NCT03525574).

\section{Participants}

Males and females aged $\geq 12$ years with a confirmed diagnosis of CF homozygous for F508del, ppFEV ${ }_{1}$ between 40 and 90 inclusive,${ }^{17}$ and stable CF as judged by the investigators were recruited. All participants agreed to continue their usual standard-of-care treatment regimens throughout the trial period. The full inclusion and exclusion criteria are provided in the appendix.

\section{Outcomes}

The primary endpoint was the absolute change from baseline in $\mathrm{ppFEV}_{1}$ at week 4 . Key secondary endpoints were the absolute change from baseline at week 4 in sweat chloride concentration and in the respiratory domain of the Cystic Fibrosis Questionnaire-Revised (CFQR RD) score. Other secondary endpoints included safety and tolerability, as assessed by adverse events; clinical laboratory values; electrocardiograms; vital signs; and pulse oximetry.

\section{Statistical analysis}

Efficacy analyses included all randomised participants who received at least one dose of ELX/TEZ/IVA or TEZ/IVA in the treatment period. The absolute change from baseline in ppFEV 1 at week 4 was analysed using a mixed-effects model for repeated measures with change from baseline in ppFEV 1 at day 15 and week 4 as the dependent variables. The model included 
treatment group, visit, and treatment-by-visit interaction as fixed effects, with the continuous baseline $\mathrm{ppFEV}_{1}$ and age at screening ( $<18$ vs $\geq 18$ years) as covariates; the model used an unstructured covariance for the within-subject errors. The trial was designed for superiority. Assuming a within-group standard deviation of 7 percentage points and accounting for a $5 \%$ dropout rate at week 4 , based on a two-sided, two-sample t-test at a significance level of $0 \cdot 05$, a sample size of 50 participants per treatment group was expected to achieve $>90 \%$ power to detect a difference of 5 percentage points for the mean absolute change in the $p p F E V_{1}$ from baseline at week 4 between the two treatment groups. Key secondary endpoints of absolute change in sweat chloride concentration and in CFQ-R RD score were analysed using a similar mixed-effects model for repeated measures. A hierarchical testing procedure was used to control the overall type I error at an alpha of 0.05 for the primary endpoint and the key secondary endpoints tested. The safety analyses included all participants who received at least one dose of ELX/TEZ/IVA or TEZ/IVA in the treatment period. Safety data were summarised using descriptive statistics. Safety was monitored by an independent data monitoring committee.

\section{Role of the funding source}

The trial was designed by Vertex Pharmaceuticals, in collaboration with the authors. Data were collected by local site investigators and analysed by Vertex Pharmaceuticals Incorporated, in collaboration with the authors. All authors had full access to the trial data after the data were unblinded following final database lock and provided critical review and input. The corresponding author had final responsibility for the decision to submit for publication. 


\section{Results}

\section{Participant population}

240 A total of 113 participants were enrolled in the trial. Following the 4-week TEZ/IVA run-in period, 241107 participants were randomised and received at least one dose of trial drug; 55 were in the 242 ELX/TEZ/IVA group and 52 were in the TEZ/IVA group. All 107 participants completed the 4243 week treatment period and entered the open label ELX/TEZ/IVA extension trial (figure S1). 244 Demographics and baseline characteristics were similar between intervention groups (table 1).

\section{Efficacy}

247 Treatment with ELX/TEZ/IVA led to a rapid improvement in ppFEV ${ }_{1}$ above the baseline 248 established after 4 weeks of treatment with TEZ/IVA (figure 2; table 2). The least squares mean difference between ELX/TEZ/IVA and TEZ/IVA in absolute ppFEV ${ }_{1}$ was $10 \cdot 0$ percentage points $(95 \% \mathrm{Cl} 7 \cdot 4$ to $12 \cdot 6, \mathrm{p}<0 \cdot 0001)$ at week 4.

Consistent with the clinically and statistically significant improvements observed in ppFEV ${ }_{1}$, ELX/TEZ/IVA resulted in an improvement in sweat chloride concentration, with a least squares mean treatment difference of $-45 \cdot 1 \mathrm{mmol} / \mathrm{L}$ at week $4(95 \% \mathrm{Cl}-50 \cdot 1$ to $-40 \cdot 1, \mathrm{p}<0 \cdot 0001)$ compared with the TEZ/IVA group (figure $3 \mathrm{~A}$; table 2); the resulting mean value is below the diagnostic threshold for CF (figure 3B). ${ }^{18,19}$ The treatment difference in the change in CFQ-R RD score compared with TEZ/IVA was $17 \cdot 4$ points $(95 \% \mathrm{Cl} 11 \cdot 8$ to $23 \cdot 0, \mathrm{p}<0 \cdot 0001)$. In the ELX/TEZ/IVA group, there was a least squares mean increase in the CFQ-R RD score of 16.0 points (95\% Cl $12 \cdot 1$ to $19 \cdot 9)$ (figure 4; table 2), which exceeds the known 4-point improvement corresponding to the minimal clinically important difference in pwCF with stable disease. ${ }^{20}$ 
The improvements in $\mathrm{ppFEV}_{1}$ and sweat chloride concentration were consistent across all subgroups evaluated (figures S2 and S3). The histogram of treatment response for ppFEV $V_{1}$, sweat chloride concentration, and CFQ-R RD score are shown in figures S4, S5, and S6.

At Week 4, treatment with ELX/TEZ/IVA resulted in a least squares mean increase in BMI of $0.60 \mathrm{~kg} / \mathrm{m}^{2}(95 \% \mathrm{Cl} 0.41$ to 0.79 , nominal $p<0.0001)$ and a least squares mean body weight increase of $1.6 \mathrm{~kg}(95 \% \mathrm{Cl} 1 \cdot 0$ to $2 \cdot 1$, nominal $p<0 \cdot 0001)$ compared with TEZ/IVA. Because these analyses were not pre-defined, they were not corrected for multiplicity and $p$ values are considered nominal.

\section{Safety}

ELX/TEZ/IVA was generally safe and well tolerated in this 4-week trial. Adverse events occurred in $32(58 \%)$ participants in the ELX/TEZ/IVA group and in $33(63 \%)$ participants in the TEZ/IVA group (table 3). The vast majority of AEs resolved during the study. No participants in the ELX/TEZ/IVA group and one (2\%) in the TEZ/IVA group had an adverse event reported as severe. All other adverse events were mild or moderate. There were no adverse events that led to discontinuation of trial regimen in either treatment group. Serious adverse events occurred in two (4\%) participants in the ELX/TEZ/IVA group (rash in one participant and pulmonary exacerbation in another) and one (2\%) participant in the TEZ/IVA group (pulmonary exacerbation). The most common adverse events, those that occurred in $>10 \%$ of participants in either treatment group, were cough and pulmonary exacerbation. Cough occurred more frequently in the ELX/TEZ/IVA group (15\% vs $8 \%)$, whereas pulmonary exacerbation occurred more often in the TEZ/IVA group ( $2 \%$ vs $12 \%$ ). Adverse events occurring in at least four participants in either treatment group are shown in table 3. 
Investigators reported elevated transaminase levels as adverse events in two (4\%) participants in the ELX/TEZ/IVA group and in one (2\%) participant in the TEZ/IVA group; each investigator assessed the event as mild in severity and not serious. Review of laboratory results showed an incidence of alanine transaminase or aspartate transaminase $>3 \times,>5 \times$, and $>8 \times$ the upper limit of normal in four (7\%), two (4\%), and zero participants in the ELX/TEZ/IVA group, respectively, compared with zero participants at any of these thresholds in the TEZ/IVA group. No participants had elevations of ALT/AST $>3 \times$ upper limit of normal concurrent with an elevation in total bilirubin $>2 \times$ upper limit of normal. No transaminase elevations required study drug interruption or discontinuation in this study.

Rash was seen in two (4\%) participants in the ELX/TEZ/IVA group and two (4\%) participants in the TEZ/IVA group. All four participants with rash were female, and all events were mild in severity; none required interruption or discontinuation of trial drugs. Both rash events in participants receiving ELX/TEZ/IVA resolved during the trial. One participant in each treatment group who had rash was receiving a concomitant hormonal oral contraceptive; the participant receiving ELX/TEZ/IVA discontinued the hormonal oral contraceptive.

The safety profile was consistent among subgroups (age, baseline ppFEV ${ }_{1}$, gender and geographic region). There were no clinically relevant differences between the two treatment groups in vital signs, oximetry, physical examinations, laboratory abnormalities, or electrocardiogram findings.

\section{Discussion}

In this phase 3 trial in pwCF homozygous for F508del, in which all participants had a 4 week pre-treatment period with TEZ/IVA, treatment with ELX/TEZ/IVA resulted in substantial improvements in lung function, sweat chloride concentration, respiratory-related quality of life, 
313 and nutritional parameters compared with TEZ/IVA alone. Similar results were observed across

314 all subgroups. ELX/TEZ/IVA was well tolerated, with a safety profile comparable to that in the

315 control group using TEZ/IVA alone. The most commonly reported adverse events were

316 consistent with typical manifestations of CF.

318 To date, clinical results following treatment with IVA in pwCF with the G551D mutation are 319 considered to be the benchmark for treatment with CFTR modulators. Following 24 weeks of 320 IVA therapy, the 10.6 percentage point increase in $\mathrm{ppFEV}_{1}$ and a substantial reduction in 321 pulmonary exacerbations compared with placebo ${ }^{7}$ were sustained in a 96-week trial. ${ }^{21}$ IVA 322 therapy has also been shown to be associated with a decreased need for lung transplant and 323 improved survival with long-term use. ${ }^{22,23}$ Comparatively, pwCF homozygous for F508del treated with TEZ/IVA experienced a 4-percentage point increase in $\mathrm{ppFEV}_{1}$ compared with placebo. ${ }^{12}$ The 10.0-percentage point improvement in lung function with ELX/TEZ/IVA compared with TEZ/IVA in pwCF homozygous for F508del observed in the current trial is similar to that seen with IVA in pwCF and the G551D mutation. ${ }^{7}$ Data from the 96 -week open-label study of ELX/TEZ/IVA in pwCF who are homozygous or heterozygous for F508del (NCT03525574) will be obtained to confirm these outcomes over a longer period of time.

To understand how the effects of ELX/TEZ/IVA in pwCF homozygous for F508de/ would have compared if a placebo control, rather than an active control, had been used, the improvements in clinical outcomes and CFTR function previously reported for TEZ/IVA over placebo in this population should be considered. In the current trial, participants started ELX/TEZ/IVA after a run-in with TEZ/IVA. The treatment effect of TEZ/IVA is reflected in the baseline sweat chloride concentration of $90 \mathrm{mmol} / \mathrm{L}$, which is comparable to that observed at the end of the TEZ/IVA versus placebo trial, ${ }^{12}$ and approximately $10 \mathrm{mmol} / \mathrm{L}$ below that in untreated pwCF homozygous 
concentration of $48.0 \mathrm{mmol} / \mathrm{L}$ at week 4 , which is below the diagnostic threshold for CF (60 $\mathrm{mmol} / \mathrm{L}){ }^{18}$ Likewise, the improvements in lung function (10 percentage points in ppFEV ${ }_{1}$ ) observed with ELX/TEZ/IVA compared with TEZ/IVA in the present trial may be taken in context with the demonstrated impact of TEZ/IVA in this population (a 4-percentage point improvement in $\mathrm{ppFEV} \mathrm{V}_{1}$ compared with placebo). ${ }^{12}$ It is useful to frame these results observed in trial participants taking ELX/TEZ/IVA, and the magnitude of CFTR modulation they represent, in the context of the overall degree of CFTR modulation and the clinical benefits observed in pwCF and a G551D mutation treated with IVA. ${ }^{7}$

Benefits of ELX/TEZ/IVA were also observed on other important endpoints, including surrogates for nutritional health. Although the treatment duration in this trial was only 4 weeks, there was an increase in BMI and weight in the ELX/TEZ/IVA group compared with those who received TEZ/IVA alone. Improvements in weight and BMI were not observed in a 24-week study of TEZ/IVA in the same population. ${ }^{12}$ Weight and BMI in pwCF are closely correlated with improvements in lung function and are independent predictors of survival. ${ }^{24,25}$ The improvements in weight and BMI over 4 weeks observed herein are promising.

Pulmonary exacerbations are important life events for pwCF and are associated with a greater rate of lung function decline and decreased survival. ${ }^{24,26}$ Although not defined as an efficacy outcome in this 4-week trial, there was a reduction in reported adverse events of infective pulmonary exacerbation of CF in the ELX/TEZ/IVA group relative to the TEZ/IVA group. These results and those observed in the longer companion trial in pwCF heterozygous for F508del in which treatment with ELX/TEZ/IVA resulted in a $63 \%$ reduction in pulmonary exacerbations compared with placebo ${ }^{27}$ provide encouraging evidence of the effect of ELX/TEZ/IVA on pulmonary exacerbations compared with the current standard of care. 
365 The majority of phase 3 trials assessing the efficacy of CFTR modulators have used treatment periods of 24 weeks or longer, and a potential limitation of this trial is the 4-week duration.7,11,12 However, a 4-week duration was selected for this trial based on (1) observations that short-term changes in lung function have consistently been demonstrated within 4 weeks of treatment with CFTR modulators in previous randomised controlled trials, and these short-term improvements in lung function have been sustained through 24 weeks of treatment, ${ }^{7,11,12}$ and (2) the premise that the safety profile observed in the concurrent 24-week trial of ELX/TEZ/IVA in pwCF heterozygous for $F 508 d e{ }^{27}$ would be applicable to pwCF homozygous for F508del. The latter assumption is supported by prior data with CFTR modulators showing comparable safety data across numerous CF genotypes. ${ }^{7,8,28}$ Long-term outcomes of ELX/TEZ/IVA in will be evaluated in ongoing investigations including the open-label extension of this trial and post approval observational studies. participants homozygous for F508del over the 4-week study period. In the concurrent phase 3 trial in pwCF in whom a single F508del was responsible for the treatment response, marked 381 improvements in clinical outcomes substantiate the ability of ELX/TEZ/IVA to restore F508del382 CFTR function. ${ }^{27}$ Based on the known impact of the benchmark therapy IVA in a small subset of pwCF, the introduction of ELX/TEZ/IVA is likely to lead to meaningful improvements in the lives of pwCF homozygous for F508del. This degree of CFTR modulation in such a large proportion of pwCF may profoundly impact the face of CF care.

\section{Author contributions}

388 The VX17-445-103 study was designed by the study sponsor, Vertex Pharmaceuticals 389 Incorporated, in collaboration with EFC, SMR, ET, MAM, BWR, and JLT-C. HGMH, DGD, EVB, 390 JJW, JLT-C, and KSM enrolled participants, and collected the data, which were analysed by the 
391

392 393 394 395

sponsor. All authors participated in the analysis and interpretation of study data, drafting and critically revising the manuscript for important intellectual content, and gave final approval of the manuscript for publication.

\section{Declaration of interest}

HGMH reports speaker fees from Chiesi, Horizon Pharma, PTC Therapeutics, TEVA, and Vertex; fees for advisory board participation from Vertex and PTC Therapeutics. EFM reports grants from Gilead and Vertex, for which his institution St Vincent's University Hospital received payment; consulting fees from Vertex and Proteostasis; non-financial support from Novartis. DGD reports grants from Proteostasis and Vertex, for which his institution Queen's University Belfast received payment; speaker fees from Vertex; honoraria from Proteostasis. EVB reports research grants from Vertex, Galapagos and Zambon, for which her institution Ghent University Hospital received payment; fees for advisory board participation for Vertex. SMR reports research grants from AstraZeneca, Bayer, Celtaxys, Eloxx, Forest Research Institute, Galapagos/AbbVie, N30/Nivalis, Novartis, PTC Therapeutics, and Vertex, for which his institution the University of Alabama at Birmingham received payment; consulting fees from Bayer, Celtaxys, Novartis, Renovion, and Vertex; fees for advisory board participation for Vertex. ET reports grants from AbbVie, Proteostasis, and Vertex, for which her institution St Michael's Hospital received payment; personal fees from Proteostasis and Vertex. MAM reports research grants from Vertex, for which his institution Charité-Universitätsmedizine Berlin received payment; consulting fees from Bayer, Galapagos, and Sterna Biologicals; fees for consulting and advisory board participation from Arrowhead, Boehringer Ingelheim, Enterprise Therapeutics, Polyphor, ProQR Therapeutics, Sathera, Spyryx Bioscience, and Vertex; speaker fees from Bayer, Boehringer Ingelheim, Celtaxys, and Vertex. JJW reports grants from Concert, Proteostasis, and Vertex, for which his institution New York Medical College received payment. CMM, GM, SMM, DW, PRS, CS, NA, FX, and YZ are employees of Vertex and may own stock 
417 or stock options in that company. JLT-C reports research grants from Celtaxys, Bayer, Gilead,

418 National Institutes of Health, Proteostasis, the Cystic Fibrosis Foundation, and Vertex, for which

419 her institution National Jewish Health received payment; consulting fees from Celtaxys,

420 Proteostasis, Santhera, and Vertex; fees for advisory board participation from Gilead, Protalix,

421 and Vertex; speaker fees from Celtaxys, Proteostasis, and Vertex; and service on the Cystic

422 Fibrosis Foundation Therapeutics Development Network Clinical Research Executive

423 Committee and as Chair-Elect of the American Thoracic Society Clinical Problems Assembly

424 Programming Committee. KSM reports research grants from Alcresta, Corbus, Novoteris,

425 Proteostasis, Savara, Translate Bio, and Vertex, for which her institution Nationwide Children's

426 Hospital received payment. BWR has nothing to disclose.

427

\section{Data sharing}

429 Vertex Pharmaceuticals Incorporated is committed to advancing medical science and improving

430 patient health. This commitment includes the responsible sharing of clinical trial data with

431 qualified researchers. Proposals for the use of these data will be reviewed by a scientific board.

432 Approvals are at the discretion of Vertex Pharmaceuticals Incorporated and will be dependent

433 on the nature of the request, the merit of the research proposed, and the intended use of the

434 data. Please contact CTDS@vrtx.com if you would like to submit a proposal or need more

435 information.

\section{Acknowledgements}

438 We thank the participants and their families for participating and the study investigators and

439 coordinators for their contributions to the study. We thank the Cystic Fibrosis Foundation

440 Therapeutics Development Network and the European Cystic Fibrosis Clinical Trials Network for

441 their support of the study sites. The study was supported by Vertex Pharmaceuticals

442 Incorporated. The National Institutes of Health provided grant support to the University of 
443 Alabama at Birmingham (P30DK072482, R35HL135816, and U54TR001368) and Seattle 444 Children's Hospital (P30-DK-089507, 5UL1 TR 0002319, and 1U01TR 002487). Editorial 445 coordination and support were provided by Sarah Garber, PharmD and Swati Thorat, PhD. SG 446 and ST are employees of Vertex Pharmaceuticals Incorporated and may own stock or stock 447 options in the company. Editorial assistance was provided by Katherine Mills-Lujan, PhD, CMPP 448 of ArticulateScience LLC under the guidance of the authors and was supported by Vertex 449 Pharmaceuticals Incorporated.

450 
453

454

455

456

457

458

459

460

461

462

463

464

465

466

467

468

469

470

471

472

473

474

475

476

477

478

479

480

481

482

483

484

485

486

487

488

489

490

491

492

493

494

495

496

497

498

499

500

501

1. Elborn JS. Cystic fibrosis. Lancet 2016; 388: 2519-31.

2. Dalemans W, Barbry P, Champigny $G$, et al. Altered chloride ion channel kinetics associated with the delta F508 cystic fibrosis mutation. Nature 1991; 354: 526-8.

3. Charman S, Connon R, Cosgriff R, Lee A, Carr S. UK Cystic Fibrosis Registry. Annual Data Report 2017. London, UK: Cystic Fibrosis Trust; 2018.

4. Zolin A, Orenti A, van Rens J, et al. ECFSPR Annual Report 2017. Karup, Denmark: European Cystic Fibrosis Society; 2019.

5. Marshall B, Faro A, Fink AK, et al. Cystic Fibrosis Patient Registry. 2017 Annual Data Report. Bethesda, MD; Cystic Fibrosis Foundation; 2018.

6. Cystic Fibrosis Mutation Database. CFMDB Statistics. April 25, 2011. http://www.genet.sickkids.on.ca/StatisticsPage.html (accessed August 23, 2019).

7. Ramsey BW, Davies J, McElvaney NG, et al. A CFTR potentiator in patients with cystic fibrosis and the G551D mutation. N Engl J Med 2011; 365: 1663-72.

8. Flume PA, Liou TG, Borowitz DS, et al. Ivacaftor in subjects with cystic fibrosis who are homozygous for the F508del-CFTR mutation. Chest 2012; 142: 718-24.

9. Welsh MJ, Denning GM, Ostedgaard LS, Anderson MP. Dysfunction of CFTR bearing the delta F508 mutation. J Cell Sci Suppl 1993; 17: 235-9.

10. Lukacs GL, Chang XB, Bear C, et al. The delta F508 mutation decreases the stability of cystic fibrosis transmembrane conductance regulator in the plasma membrane. Determination of functional half-lives on transfected cells. J Biol Chem 1993; 268: 21592-8.

11. Wainwright CE, Elborn JS, Ramsey BW, et al. Lumacaftor-ivacaftor in patients with cystic fibrosis homozygous for Phe508del CFTR. N Engl J Med 2015; 373: 220-31.

12. Taylor-Cousar JL, Munck A, McKone EF, et al. Tezacaftor-ivacaftor in patients with cystic fibrosis homozygous for Phe508del. N Engl J Med 2017; 377: 2013-23.

13. Rabeh WM, Bossard $F, X u H$, et al. Correction of both NBD1 energetics and domain interface is required to restore $\triangle F 508$ CFTR folding and function. Cell 2012; 148: 150-63.

14. Mendoza JL, Schmidt A, Li Q, et al. Requirements for efficient correction of $\triangle F 508$ CFTR revealed by analyses of evolved sequences. Cell 2012; 148: 164-74.

15. Keating D, Marigowda G, Burr L, et al. VX-445-tezacaftor-ivacaftor in patients with cystic fibrosis and one or two Phe508del alleles. N Engl J Med 2018; 379: 1612-20.

16. Taylor-Cousar JL, Mall MA, Ramsey BW, et al. Clinical development of triple-combination CFTR modulators for cystic fibrosis patients with one or two F508del alleles. ERJ Open Res 2019; 5: pii: 00082-2019.

17. Quanjer PH, Stanojevic S, Cole TJ, et al. Multi-ethnic reference values for spirometry for the 3-95-yr age range: the global lung function 2012 equations. Eur Respir J 2012; 40: 1324-43.

18. Farrell PM, White TB, Ren CL, et al. Diagnosis of Cystic Fibrosis: Consensus Guidelines from the Cystic Fibrosis Foundation. J Pediatr 2017; 181S: S4-S15.e1.

19. Castellani C, Duff AJA, Bell SC, et al. ECFS best practice guidelines: the 2018 revision. $J$ Cyst Fibros 2018; 17: 153-78.

20. Quittner AL, Modi AC, Wainwright C, Otto K, Kirihara J, Montgomery AB. Determination of the minimal clinically important difference scores for the Cystic Fibrosis QuestionnaireRevised respiratory symptom scale in two populations of patients with cystic fibrosis and chronic Pseudomonas aeruginosa airway infection. Chest 2009; 135: 1610-8.

21. McKone EF, Borowitz $D$, Drevinek $P$, et al. Long-term safety and efficacy of ivacaftor in patients with cystic fibrosis who have the Gly551Asp-CFTR mutation: a phase 3, open-label extension study (PERSIST). Lancet Respir Med 2014; 2: 902-10.

22. Bessonova L, Volkova N, Higgins M, et al. Data from the US and UK cystic fibrosis registries support disease modification by CFTR modulation with ivacaftor. Thorax 2018; 73: 731-40. 
23. Volkova N, Moy K, Evans J, et al. Disease progression in patients with cystic fibrosis treated with ivacaftor: Data from national US and UK registries. J Cyst Fibros 2019 Jun 10 [Epub ahead of print].

24. Liou TG, Adler FR, Fitzsimmons SC, Cahill BC, Hibbs JR, Marshall BC. Predictive 5-year survivorship model of cystic fibrosis. Am J Epidemiol 2001; 153: 345-52.

25. Yen EH, Quinton H, Borowitz D. Better nutritional status in early childhood is associated with improved clinical outcomes and survival in patients with cystic fibrosis. J Pediatr 2013; 162(3): 530-5 e1.

26. Waters V, Stanojevic S, Atenafu EG, et al. Effect of pulmonary exacerbations on long-term lung function decline in cystic fibrosis. Eur Respir J 2012; 40: 61-6.

27. Middleton PG, Mall MA, Drevinek $P$, et al. Elexacaftor-tezacaftor-ivacaftor for $C F$ with a single Phe509del mutation. N Engl J Med 2019 (submitted).

28. Rowe SM, McColley SA, Rietschel E, et al. Lumacaftor/ivacaftor treatment of patients with cystic fibrosis heterozygous for F508del-CFTR. Ann Am Thorac Soc 2017; 14: 213-9. 
517 Table 1. Demographics and Clinical Characteristics at Baseline.*

\begin{tabular}{|c|c|c|}
\hline & $\begin{array}{l}\text { Tezacaftor/lvacaftor } \\
\qquad(n=52)\end{array}$ & $\begin{array}{l}\text { Elexacaftor/Tezacaftorl } \\
\text { Ivacaftor } \\
(n=55)\end{array}$ \\
\hline Female gender — no. (\%) & $28(54)$ & $31(56)$ \\
\hline \multicolumn{3}{|l|}{ Age at baseline } \\
\hline Mean - yr & $27 \cdot 9 \pm 10 \cdot 8$ & $28 \cdot 8 \pm 11 \cdot 5$ \\
\hline \multicolumn{3}{|l|}{ Distribution - no. $(\%)^{\dagger}$} \\
\hline$\geq 12$ to $<18 \mathrm{yr}$ & $14(27)$ & $16(29)$ \\
\hline$\geq 18 \mathrm{yr}$ & $38(73)$ & $39(71)$ \\
\hline \multicolumn{3}{|l|}{$\begin{array}{l}\text { Geographic region - no. } \\
(\%)\end{array}$} \\
\hline North America & $33(63)$ & $34(62)$ \\
\hline Europe & $19(37)$ & $21(38)$ \\
\hline \multicolumn{3}{|l|}{$\begin{array}{l}\text { Percentage of predicted } \\
\text { FEV }_{1}\end{array}$} \\
\hline Mean & $60 \cdot 2 \pm 14 \cdot 4$ & $61 \cdot 6 \pm 15 \cdot 4$ \\
\hline \multicolumn{3}{|l|}{ Distribution - no. (\%) } \\
\hline$<40 \%^{\ddagger}$ & $4(8)$ & $6(11)$ \\
\hline$\geq 40 \%$ to $<70 \%$ & $34(65)$ & $31(56)$ \\
\hline$\geq 70 \%$ to $\leq 90 \%$ & $14(27)$ & $18(33)$ \\
\hline$>90 \%$ & 0 & 0 \\
\hline Body-mass index, mean§ & $21 \cdot 88 \pm 4 \cdot 12$ & $21 \cdot 75 \pm 3 \cdot 19$ \\
\hline
\end{tabular}


Page 24

\begin{tabular}{|c|c|c|}
\hline $\begin{array}{l}\text { Sweat chloride } \\
\text { concentration, mean - } \\
\mathrm{mmol} / \mathrm{L}\end{array}$ & $90 \cdot 0 \pm 12 \cdot 3$ & $91 \cdot 4 \pm 11 \cdot 0$ \\
\hline $\begin{array}{l}\text { CFQ-R respiratory } \\
\text { domain score, mean" }\end{array}$ & $72 \cdot 6 \pm 17 \cdot 9$ & $70 \cdot 6 \pm 16 \cdot 2$ \\
\hline $\begin{array}{l}\text { Pseudomonas } \\
\text { aeruginosa-positive within } \\
\text { previous } 2 \text { years - no. } \\
(\%)\end{array}$ & $31(60)$ & $39(71)$ \\
\hline $\begin{array}{l}\text { Prior medication use, } \mathrm{n} \\
(\%)^{\pi}\end{array}$ & & \\
\hline Dornase alfa & & \\
\hline Yes & $48(92)$ & $51(93)$ \\
\hline No & $4(8)$ & $4(7)$ \\
\hline Azithromycin & & \\
\hline Yes & $25(48)$ & $33(60)$ \\
\hline No & $27(52)$ & $22(40)$ \\
\hline Inhaled antibiotic & & \\
\hline Yes & $28(54)$ & $35(64)$ \\
\hline No & $24(46)$ & $20(36)$ \\
\hline Bronchodilator & & \\
\hline Yes & $47(90)$ & $54(98)$ \\
\hline No & $5(10)$ & $1(2)$ \\
\hline Inhaled hypertonic saline & & \\
\hline Yes & $41(79)$ & $38(69)$ \\
\hline
\end{tabular}




\begin{tabular}{|l|l|l|}
\hline No & \multicolumn{1}{|c|}{$11(21)$} & $17(31)$ \\
\hline Inhaled corticosteroids & $28(54)$ & $36(65)$ \\
\hline Yes & $24(46)$ & $19(35)$ \\
\hline No & & \\
\hline CFTR modulator therapy & & $32(58)$ \\
\hline Yes & $34(65)$ & $23(42)$ \\
\hline No & $18(35)$ & \\
\hline
\end{tabular}

$\mathrm{CFQ}-\mathrm{R}=$ Cystic Fibrosis Questionnaire-Revised; $\mathrm{FEV}_{1}=$ forced expiratory volume in 1 second.

519 *Plus-minus values are means \pm SD.

$520+$ Age distribution was calculated based on age at the time of screening.

$521 \mp$ Although those eligible for enrolment were required to have a percent predicted $\mathrm{FEV}_{1} \geq 40$ at screening, 522 some participants experienced a decrease to a value $<40$ by baseline.

523 \& The body-mass index is the weight in kilograms divided by the square of the height in meters.

524 " Scores on the CFQ-R range from 0 to 100 , with higher scores indicating a higher participant-reported 525 quality of life with regard to respiratory status.

$526 \pi$ Includes medications administered during the 56 days before the first dose of trial drug in the treatment 527 period. 
Table 2. Primary and Secondary Efficacy End Points.*

\begin{tabular}{|c|c|c|c|c|}
\hline & $\begin{array}{l}\text { Tezacaftorl } \\
\text { Ivacaftor } \\
(n=52)\end{array}$ & $\begin{array}{l}\text { Elexacaftorl } \\
\text { Tezacaftorl } \\
\text { Ivacaftor } \\
(n=55)\end{array}$ & $\begin{array}{l}\text { Difference } \\
\qquad(95 \% \mathrm{Cl})\end{array}$ & $\begin{array}{c}P \\
\text { Value }^{\dagger}\end{array}$ \\
\hline \multicolumn{5}{|l|}{ Primary endpoint } \\
\hline $\begin{array}{l}\text { Absolute change in percentage of } \\
\text { predicted FEV } 1 \text { from baseline at week } 4 \\
(95 \% \mathrm{Cl}) \text { - percentage points }\end{array}$ & $\begin{array}{c}0 \cdot 4 \\
(-1 \cdot 4,2 \cdot 3)\end{array}$ & $\begin{array}{c}10 \cdot 4 \\
(8 \cdot 6,12 \cdot 2)\end{array}$ & $\begin{array}{c}10 \cdot 0 \\
(7 \cdot 4,12 \cdot 6)\end{array}$ & $<0.0001$ \\
\hline \multicolumn{5}{|l|}{ Key secondary endpoints } \\
\hline $\begin{array}{l}\text { Absolute change in sweat chloride } \\
\text { concentration from baseline at week } 4 \\
(95 \% \mathrm{Cl})-\mathrm{mmol} / \mathrm{L}\end{array}$ & $\begin{array}{c}1 \cdot 7 \\
(-1 \cdot 9,5 \cdot 3)\end{array}$ & $\begin{array}{c}-43 \cdot 4 \\
(-46 \cdot 9,-40 \cdot 0)\end{array}$ & $\begin{array}{c}-45 \cdot 1 \\
(-50 \cdot 1,-40 \cdot 1)\end{array}$ & $<0.0001$ \\
\hline $\begin{array}{l}\text { Absolute change in CFQ-R respiratory } \\
\text { domain score from baseline at week } 4 \\
(95 \% \mathrm{Cl}) \text { - points }\end{array}$ & $\begin{array}{c}-1 \cdot 4 \\
(-5 \cdot 4,2 \cdot 6)\end{array}$ & $\begin{array}{c}16 \cdot 0 \\
(12 \cdot 1,19 \cdot 9)\end{array}$ & $\begin{array}{c}17 \cdot 4 \\
(11 \cdot 8,23 \cdot 0)\end{array}$ & $<0.0001$ \\
\hline
\end{tabular}


Table 3. Adverse Events.

\begin{tabular}{|c|c|c|}
\hline & $\begin{array}{l}\text { Tezacaftor/lvacaftor } \\
\qquad(n=52)\end{array}$ & 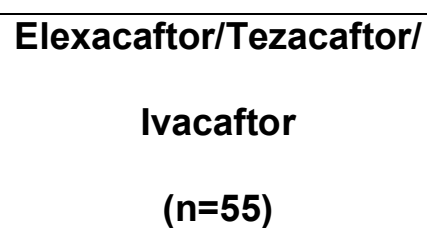 \\
\hline & \multicolumn{2}{|c|}{ number of participants (percent) } \\
\hline Any adverse event & $33(63)$ & $32(58)$ \\
\hline $\begin{array}{l}\text { Adverse event related to } \\
\text { trial drug }{ }^{\dagger}\end{array}$ & $9(17)$ & $12(22)$ \\
\hline $\begin{array}{l}\text { Adverse event, according } \\
\text { to maximum severity }\end{array}$ & & \\
\hline Mild & $21(40)$ & $23(42)$ \\
\hline Moderate & $11(21)$ & $9(16)$ \\
\hline Severe & $1(2)$ & 0 \\
\hline Life Threatening & 0 & 0 \\
\hline $\begin{array}{l}\text { Grade } 3 \text { or } 4 \text { adverse } \\
\text { event }\end{array}$ & $1(2)$ & 0 \\
\hline Serious adverse event & $1(2)$ & $2(4)$ \\
\hline $\begin{array}{l}\text { Serious adverse event } \\
\text { related to trial drug }{ }^{\dagger}\end{array}$ & 0 & $1(2)$ \\
\hline $\begin{array}{l}\text { Adverse event leading to } \\
\text { discontinuation of trial } \\
\text { drug }\end{array}$ & 0 & 0 \\
\hline $\begin{array}{l}\text { Adverse event leading to } \\
\text { death }\end{array}$ & 0 & 0 \\
\hline
\end{tabular}




\begin{tabular}{|l|c|c|}
\hline Most common adverse & & \\
\hline Counts & & \\
\hline Nasopharyngitis & $4(8)$ & $4(15)$ \\
\hline Oropharyngeal pain & $2(4)$ & $4(7)$ \\
\hline $\begin{array}{l}\text { Upper respiratory tract } \\
\text { infection }\end{array}$ & $2(4)$ & $4(7)$ \\
\hline Headache & $4(8)$ & $3(5)$ \\
\hline Haemoptysis & $5(10)$ & $2(4)$ \\
\hline Pulmonary exacerbation & $6(12)$ & $1(2)$ \\
\hline
\end{tabular}

Adverse events were coded using MedDRA version 21·1. When summarizing number and percent of participants, a participant with multiple events within a category was counted only once in that category.

t The determination of relatedness to trial drug was made by the investigators. When summarizing number of participants with (serious) adverse events related to the trial drug, adverse events with relationship of related, possibly related, and missing were counted.

$¥$ The most common adverse events were those that occurred in at least four participants in either trial group. 
548 Figure 1. Study Design. Phase 3, randomised, double-blind, active-controlled, parallel-group,

549 multicentre study. Eligible participants received tezacaftor/ivacaftor therapy during a 4-week

550 run-in period. After completing the run-in period participants were randomised (1:1) to receive

551 elexacaftor/tezacaftor/ivacaftor triple combination therapy or tezacaftor/ivacaftor for 4 weeks.

552 Randomisation was stratified by percent predicted $\mathrm{FEV}_{1}(<70$ vs $\geq 70)$ determined during the

553 run-in period and age ( $<18$ vs $\geq 18$ years) determined at the screening visit. ELX=elexacaftor;

$554 \mathrm{FEV}_{1}=$ forced expiratory volume in 1 second; IVA=ivacaftor; $\mathrm{QAM}=$ once daily in the morning;

555 QPM=once daily in the evening; TEZ=tezacaftor.

$556{ }^{*}$ Baseline was defined as the most recent non-missing measurement (scheduled or

557 unscheduled) collected before the first dose of trial drug in the treatment period (ie,

558 ELX/TEZ/IVA vs TEZ/IVA).

$559+$ Participants who completed the trial regimen were eligible to enrol in a separate 96-week

560 open-label extension study within 28 days after the last dose of trial drug; a safety follow-up visit

561 was required for all participants unless they completed the week 4 visit and enrolled in the open-

562 label extension study.

563

\begin{tabular}{|c|c|c|c|}
\hline \multirow{3}{*}{$\begin{array}{l}\text { Screening } \\
\text { Period }\end{array}$} & Run-In Period & Treatment Period & \multirow{3}{*}{$\begin{array}{c}\text { Safety } \\
\text { Follow-Up }\end{array}$} \\
\hline & \multirow{2}{*}{$\begin{array}{c}\text { TEZ/IVA } \\
\text { (TEZ } 100 \text { mg/IVA } 150 \mathrm{mg} \text { QAM } \\
+ \text { + IVA } 150 \mathrm{mg} \text { QPM) }\end{array}$} & $\begin{array}{c}\text { ELX/TEZ/IVA } \\
\text { (ELX } 200 \text { mg/TEZ } 100 \mathrm{mg} / \\
\text { IVA } 150 \mathrm{mg} \text { QAM + IVA } 150 \mathrm{mg} \text { QPM) }\end{array}$ & \\
\hline & & $\begin{array}{c}\text { TEZ/IVA } \\
\text { (TEZ } 100 \text { mg/IVA } 150 \mathrm{mg} \text { QAM } \\
+ \text { IVA } 150 \mathrm{mg} \text { QPM) }\end{array}$ & \\
\hline \multirow[t]{2}{*}{$\begin{array}{c}\text { Day }-56 \text { to } \\
\text { Day }-29\end{array}$} & Day -28 to Day -1 & 4 Weeks & 28 Days \\
\hline & \multicolumn{2}{|c|}{ Randomisation (1:1)* } & $\begin{array}{l}\text { abel } \\
\text { Study }\end{array}$ \\
\hline
\end{tabular}


Page 30

565 Figure 2. Absolute Change Over Time in Percent Predicted Forced Expiratory Volume in 1

566 Second $\left(\right.$ ppFEV $_{1}$ ) From Baseline. Data are least squares means based on a mixed-effects

567 model for repeated measures, and error bars indicate standard errors; the dashed line indicates

568 no change from baseline (measured at the end of the tezacaftor/ivacaftor run-in).

569

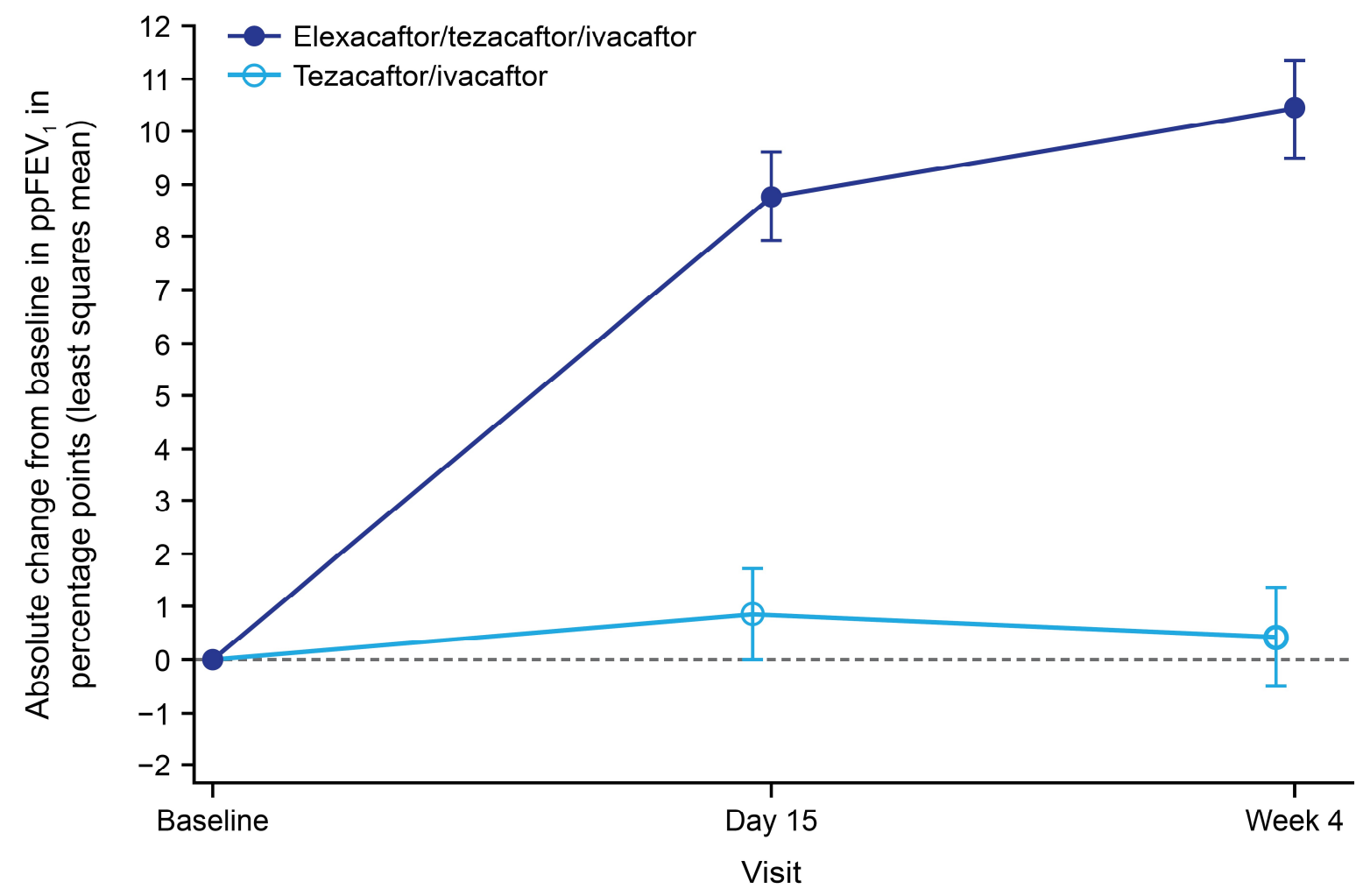


Figure 3. Absolute Change Over Time in Sweat Chloride Concentration From Baseline.

572 Panel A shows the absolute change in sweat chloride from baseline (measured at the end of the

573 tezacaftor/ivacaftor run-in period). Panel B shows the mean sweat chloride concentration for

574 each treatment group by visit. Data are least squares means based on a mixed-effects model

575 for repeated measures for panel A and sample means for panel B; error bars indicate standard

576 errors; the dashed line in panel A indicates no change from baseline; the dotted line in panel B

577 indicates the $60 \mathrm{mmol} / \mathrm{L}$ diagnostic threshold for sweat chloride concentration. ${ }^{18}$

$578 \quad$ A

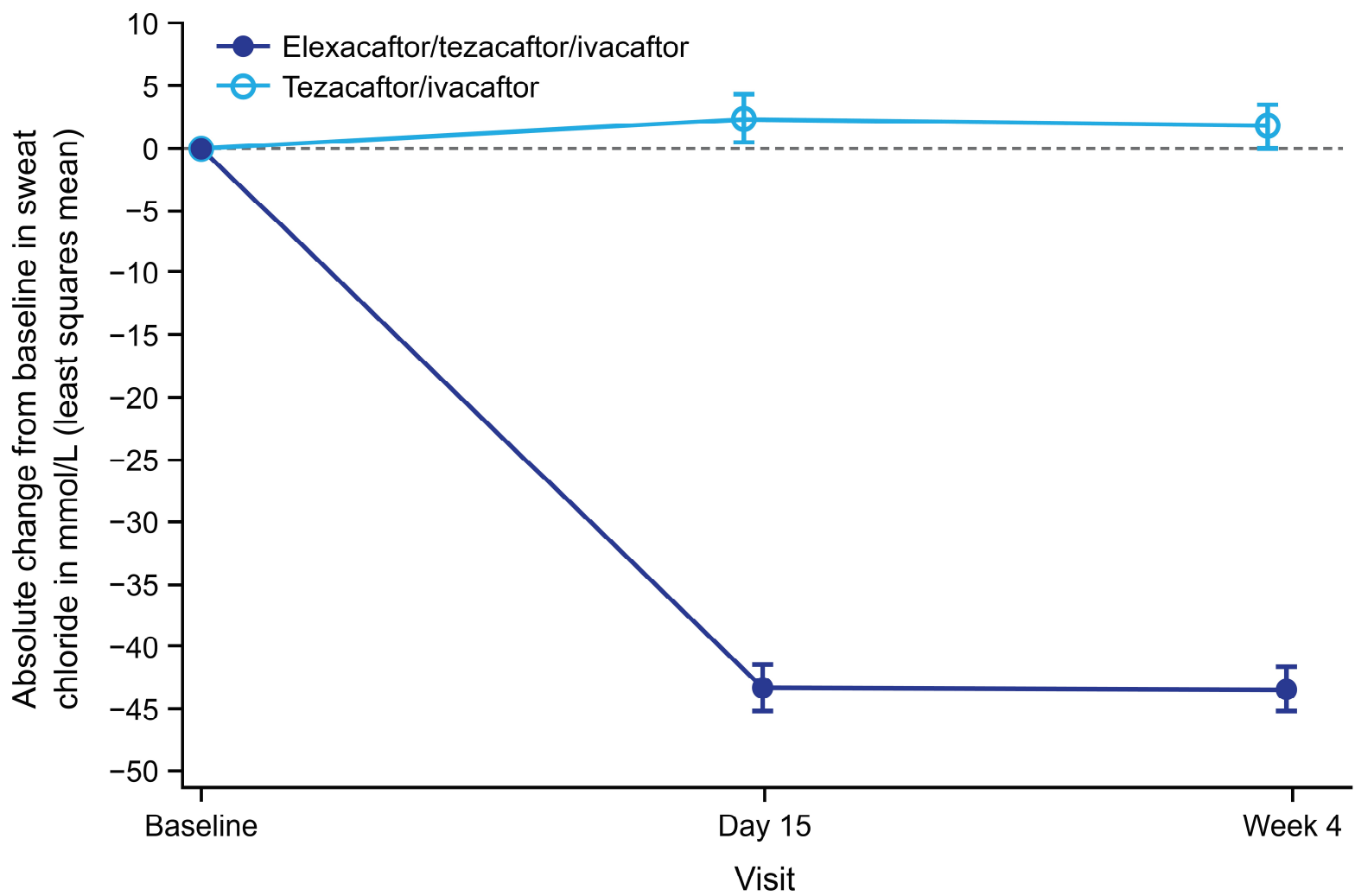

579

B 
Page 32

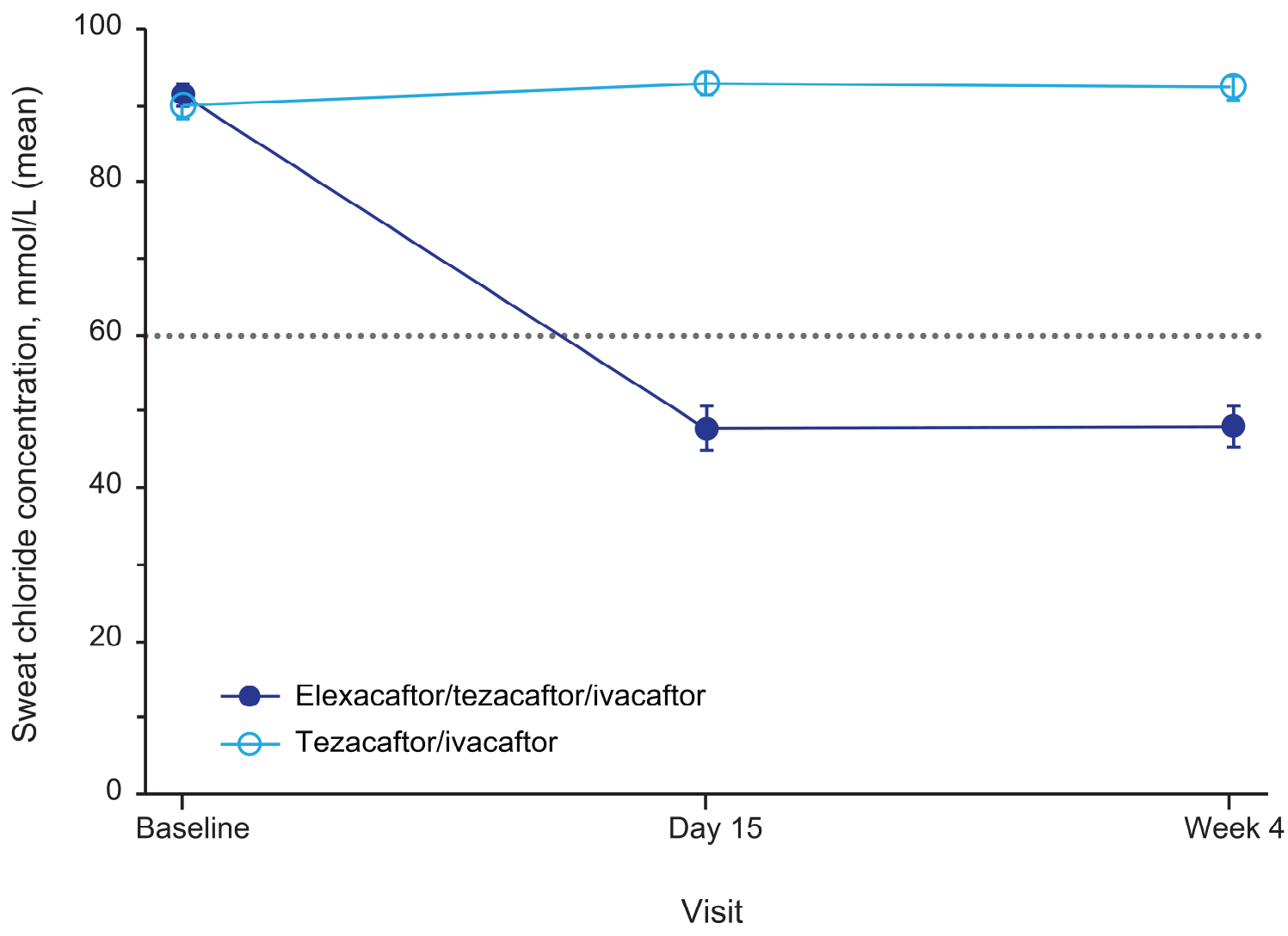


582

583 stable disease. ${ }^{20}$ CFQ-R=Cystic Fibrosis Questionnaire-Revised. 589

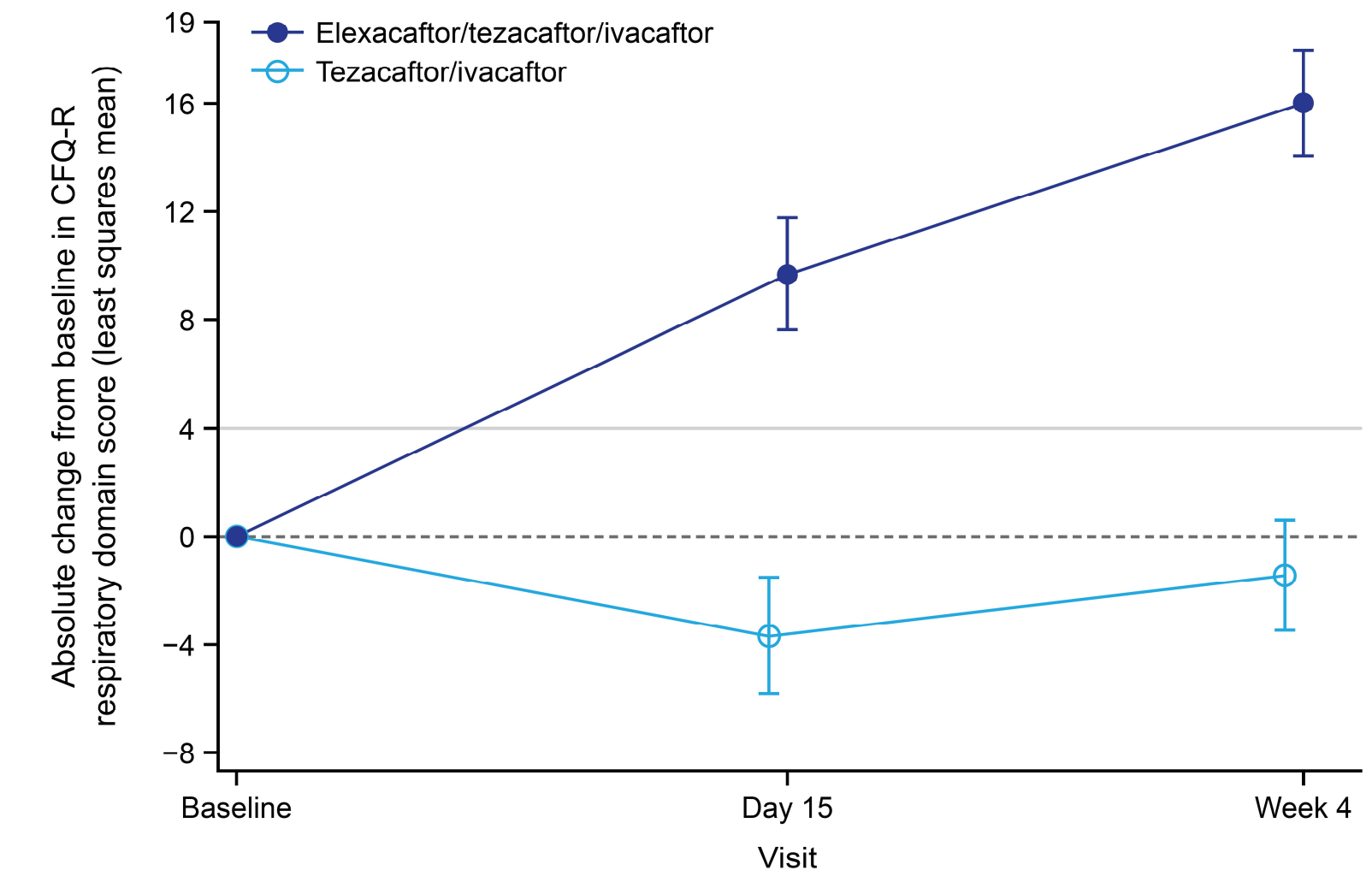

590 Figure 4. Absolute Change Over Time in Cystic Fibrosis Questionnaire-Revised Respiratory Domain Score From Baseline. Scores range from 0 to 100, with higher scores indicating a higher participant-reported quality of life with regard to respiratory status. Data are least squares mean based on a mixed-effects model for repeated measures, and error bars indicate standard errors; the dashed line indicates no change from baseline; solid light grey line indicates a change in 4 points, which is the minimal clinically important difference for pwCF with 